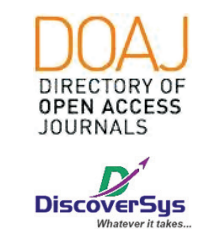

Published by DiscoverSys

${ }^{1}$ Faculty of Medicine, Universitas Katolik Indonesia Atma Jaya, Jakarta, Indonesia

\section{Self-foreign omphalitis in adult: a case report}

\author{
Daniel Ardian Soesilo, ${ }^{1}$ April Baby ${ }^{1 *}$
}

\title{
ABSTRACT
}

Introduction: Severe omphalitis in adults is rare and can be caused by both congenital and acquired etiologies. We are reporting an impacted self-foreign-body in omphalitis case induced by accumulated keratin fragments.

Case: A 28-year-old overweight male presented with a 3-day history of persistent purulent umbilical discharge with a remittent fever a few days before, constant abdominal tenderness with edema and erythema around navel area. There were no other GIT-related symptoms. He was given oral antibiotics, which showed no improvement. Upon surgery, we examined deep umbilical cavity without urachal connection to the navel. From the umbilical cavity scooped out multiple polypoid umbolith debris. Histopathologic examination revealed pyogenic granuloma with numerous keratin fragments without any foreign bodies.

Conclusion: An impacted and infected self-foreign-body may be a cause of omphalitis in adults and could lead to severe and wide-spread infection if left untreated.

Keywords: lint, omphalitis, umbilical discharge, infection.

Cite this Article: Soesilo, D.A., Baby, A. 2020. Self-foreign omphalitis in adult: a case report. Intisari Sains Medis 11(1): 129-131. D0I: 10.15562/ ism.v11i1.574

\section{INTRODUCTION}

Infection of umbilical area/omphalitis an adult is a rare but can be alarming and often lead to a more serious issue if left untreated. The overall incidence of omphalitis remains low in industrialized countries, ranging from $0.2 \%$ to $0.7 \%$ compared to $20 \%$ proportion in non-industrialized countries. ${ }^{1}$ This condition may be caused by various etiologies, whether it is congenital or acquired. Both display different clinical symptoms in sync with the extent of the disease.

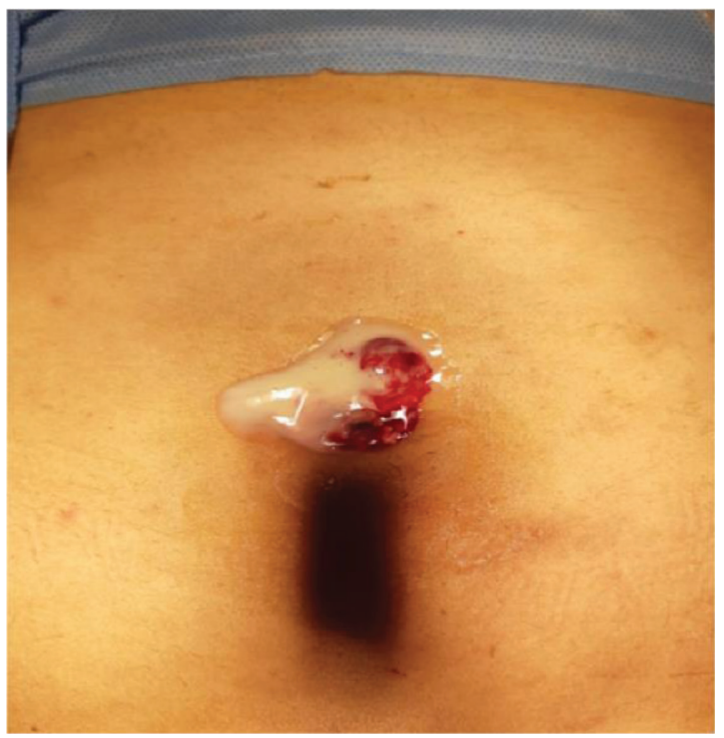

Figure 1 Umbilical purulent discharge presented in our case

\section{CASE PRESENTATION}

A 28-year-old overweight male Indonesian presented with a 3-day history of persistent purulent umbilical discharge and navel tenderness with remittent fever for a few days before admission. The pain was described as diffuse, constant, and he had the feeling of 'fullness' around his navel. He reported no episode of similar experience before. He was given oral antibiotics of clavulanic acid for 5 days prior to presentation without any improvement in his condition. He denied any nausea, diarrhea, vomiting, hematemesis, melena, urinary disturbance, and sexual dysfunction. He had no concern about his navel condition before presentation. His previous medical and surgical history was unremarkable, as well as his family/social, medical history. He took $500 \mathrm{mg}$ of paracetamol to reduce his fever. He was not on routine medications and reported none of drug/alcohol/tobacco use.

On physical examination, heart rate was 104 beats/min, respiration rate was 22 breaths/ min, blood pressure was $117 / 89 \mathrm{mmHg}$, and the body temperature was $38.8^{\circ} \mathrm{C}$ (axial temperature) with pulse oxymetry reading of $98 \%$ on room air. Yellowish, thick, and foul-odor discharge was noted from center of the umbilicus (Figure 1). The periphery of the umbilicus was erythematous with moderate tenderness and no palpable mass. Digital rectal examination was within normal limits, and his other physical examination was otherwise unremarkable. A working diagnosis of omphalitis or urachal anomalies was made. 


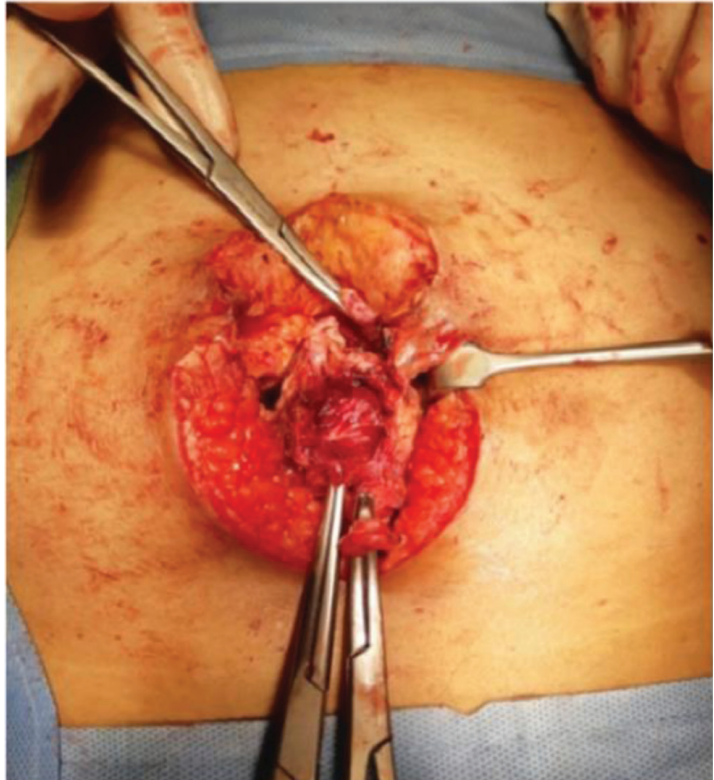

Figure 2 Exploration of umbilical area

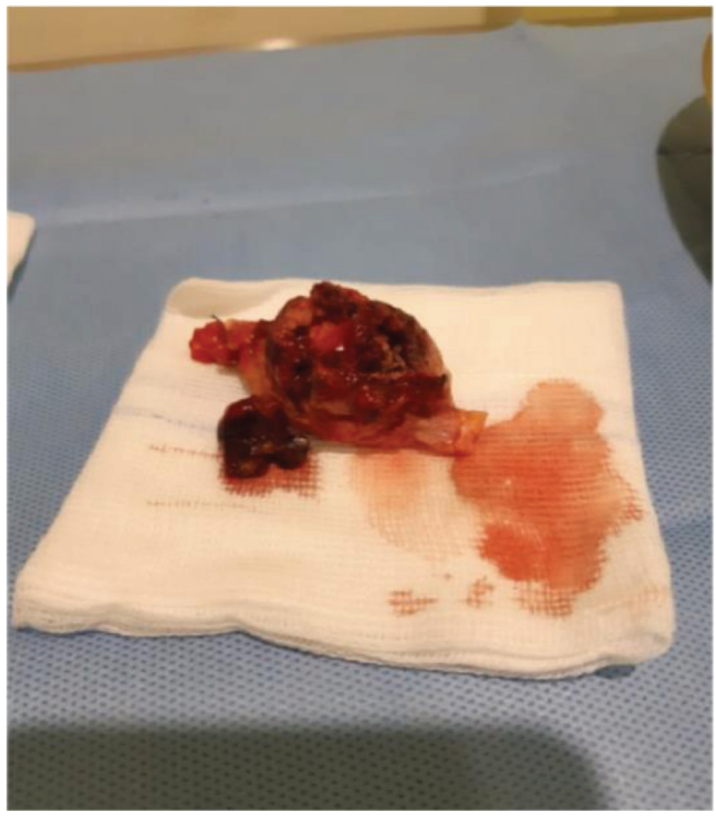

Figure 3 'Lint debris' along with necrotic umbilical tissues

Hematology workups showed leukocytosis $\left(14.5 \times 10^{3} / \mu \mathrm{L}\right)$ with left shift white cell count and a raised in C-reactive protein $(97 \mathrm{mg} / \mathrm{l})$. Basic metabolic panel, urinalysis, and stool analysis were unremarkable. Abdominal ultrasound showed normal appearance of the abdominal organ with no cavity or connection to-and-fro umbilical area, thus, a diagnosis of acquired omphalitis was made firm.

The patient was initially treated with intravenous antibiotics with surgery planned to drain the discharge and explore the umbilical area. Upon exploration, we scooped out deeper umbilical area using spatula and identified multiple white-brownish and polypoid umbolith. Our clinical impression was that of fibro-epithelial umbolith and it easily came out of the deep umbilical cavity, which means it was necrotic and not firmly attached as polyps or tumors usually are. The underlying discharge was drained. We explored the peritoneum and transversalis fascia anteriorly and found no abnormal urachal remnant. Since the umbilical cavity is hairy, deep, and grooved, we did complete umbilical stump excision to prevent recurrent omphalitis (Figure 2 and 3 ).

The patients were later treated with 7-days course of antibiotics, which consisted of 2-days intravenously and 5-days orally, and later, recovery was unremarkable. Histopathological analysis showed acute, inflamed skin tissue composed of lint material, characterized by multilayer and long-shaped keratin materials, granular debris, and various acute and chronic leukocytes with multiple bleeding points showing to be pyogenic granuloma without signs of malignancy. The patient remained asymptomatic at the later follow-up visit.

\section{DISCUSSION}

Embryologically, the urogenital sinus is connected to the umbilicus through the allantois which would be obliterated to urachus, a fibrotic tissue located in Retzius space. ${ }^{1,2}$ Failure of this obliteration causes what we know as congenital urachus. Congenital urachus can present as one of four known primary pathologies which are a urachal cyst, patent urachus/ vitelline duct, urachal sinus and vesico-urachal diverticulum, which we include as an early differential diagnosis in our patient. ${ }^{3}$ Urachal remnants are quite rare and even more uncommon in adults, as it is usually diagnosed in children. ${ }^{4}$ On the other hand, the most common causes of acquired omphalitis in adults are hair tufts with infection, pilonidal sinus, and foreign bodies. ${ }^{5}$ Endometriosis, primary tumor, and metastatic carcinoma noted as a highly rare cause of omphalitis. ${ }^{6}$ Obesity,poor hygiene, deep and hairy navel accounted as risk factors to omphalitis in adult as found in our patient. ${ }^{5,7}$

Omphalitis typically presents as superficial cellulitis, which manifested as hyperemic, tender navel with constant abdominal pain, chills or fever, and later, umbilical discharge which was found in our patient. ${ }^{8}$ The median age for omphalitis in adults ranges from 23 to 40 years of age. When treatment regarding the infection is not adequate, it can spread to involve the entire abdominal wall and may progress to necrotizing fasciitis, myonecrosis, or systemic disease. ${ }^{7}$ The commonly cultured microorganisms from the site are Escherichia coli, Enterococcus faecium, Klebsiella sp., Streptococcus viridians, Bacteroides sp.and Fusobacterium. ${ }^{9}$ 
Ultrasound scan can help to confirm the diagnosis in $77 \%$ of patients, in which worked in our case to rule out any urachal remnants. ${ }^{10}$

The present case is an omphalitis induced by 'foreign body' which was formed from his skin circumstances. Hairball is the most common type of foreign body seen in omphalitis, ${ }^{6}$ which was not the primary etiology of our case, though we did find keratin fragments in the so-called 'lint-debris'. The exciting finding is that though his navel was hairy, the major component of the foreign body was keratin material, which then became the source of infection. Usually lint-debris washed off during shower or when cleaned and rarely cause inflammation. We found a similar case report of lint-material-induced omphalitis which showed similar behavior, natural progression. However, related studies by Sarma reported multiple hair fragments as parts of 'lintball' which we found none in ours, even though there was massive hair inside the patient's navel. Steinhauser suggested that massive abdominal and umbilical hair plays a role in compacting and forming lint debris lump, thus, regular shaving can prevent lint formation in the umbilicus. ${ }^{11}$

The treatment of choice for mild omphalitis without any discharge and umbolith is by using oral antibiotics specified for the causing agent. ${ }^{4}$ The patient's previous treatment followed this guideline but failed to cease the disease entirely and suggesting remaining cause, which was later identified as lint-debris. In severe omphalitis cases with persistent purulent discharge, it is recommended to do complete surgical excision due to the risk of recurrence and malignancy potential as we did in our case. ${ }^{6,12,13}$ We used a combination of broad-spectrum antibiotics intravenously as previous oral antibiotics had proven ineffective.

Though rare, physicians may benefit from putting-in umbilical anomalies as one of the differential diagnoses when it came to a 'common' fever and abdominal tenderness with purulent discharge in adult. Once diagnosed, work-ups must be made to rule out congenital umbilical anomalies as it is will recurrent if not adequately treated.

\section{CONCLUSION}

Omphalitis is often presented by purulent umbilical discharge and is rare in adults. Presentation might be atypical if it is a mild and high index of suspicion regarding congenital umbilical anomalies is required to confirm the working diagnosis. Obesity, deep and hairy navel played a role as risk factors of omphalitis in adult. Early diagnosis and treatment may prevent subsequent progression and complication. Complete surgical removal and antibiotics stand as the treatment of choice in severe omphalitis, as seen in our case.

\section{CONFLICT OF INTEREST}

We declare no involvement in any entity with any financial interest, ownership, other equity interest or non-financial interest in the subject discussed in this publication

\section{REFERENCES}

1. Patel N. Review of Omphalitis Interventions in India, Nepal and Pakistan Using Proximal, Intermediate and Distal Risk Factors. Public Health Capstone Projects [Internet]. 2016 Oct $1^{\text {st }}$; Available from: https://scholarworks.gsu.edu/cgi/ viewcontent.cgi? article $=1015 \&$ context $=$ iph_capstone

2. Sjamsuhidajat R, Wim DJ.Textbook of Surgery. 3rd ed. Vol. 1. Jakarta: Penerbit Buku Kedokteran ECG; 2016.

3. Purnomo BB. Anatomy of Urinary Tract. In: Basic Urology. 3rd ed. Jakarta: SagungSeto; 2014. p. 225.

4. Walker C. A Case Report of Urachal Abscess: A Rare Differential in Adult Abdominal Pain. Hawai'i Med J. 2010 Feb;69.

5. Rodrigues G. Umbolith: a cause of umbilical discharge and omphalitis. Infection. 2015;43(5):62-68.

6. Sarma DP, Teruya B. Lint ball omphalitis, a rare cause of umbilical discharge in an adult woman: a case report. Cases J. 2009;2(1):7785-6.

7. Omphalitis [Internet]. Background, Pathophysiology, Etiology. 2018 [cited 2019 Apr 16 ${ }^{\text {th }}$ ]. Available from: https://emedicine.medscape.com/article/975422-overview

8. Hsu C-C, Liu Y-P, Lien W-C, Lai T-I, Chen W-J, Wang H-P. Urachal abscess: a cause of adult abdominal pain that cannot be ignored. Am J Emerg Med. 2005;23(2):229-30.

9. Ekwueme KC, Parr NJ. Infected urachal cyst in an adult: a case report and review of the literature. Cases Journal. 2009;2(1):6422-26.

10. Lucerna A, Lee J, Espinosa J, Hertz R, Scali V. An Adult with a Remnant Urachus Anomaly Diagnosed in the Emergency Department. Case Reports Emerg Med. 2018;2:1-3.

11. Steinhauser G: The nature of navel fluff. Med Hypotheses. 2009;72:623-625.

12. Ching-Ming Kwok. Infected urachal cyst in an adult: a laparoscopic approach. Case Rep Gastroenterol. 2016;10:269-274.

13. De Silva WD, Samarasinghe MC, Dias MN, Perera CS. Ectopic gastric and pancreatic tissue: a rare cause of umbilical discharge. Am Trop Paediatr. 2010;30(1):73-5.

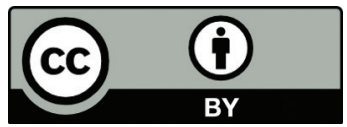

This work is licensed under a Creative Commons Attribution 